\title{
FAYGA OSTROWER: ESTUDOS SOBRE A PESQUISA PLÁSTICA E TEÓRICA NOS PROCESSOS CRIATIVOS
}

\author{
Joedy Luciana Barros Marins Bamonte ${ }^{1}$
}

\begin{abstract}
The way we look express our soul, so there is no way to disregard the presence of intuitive processes in the creation of any work, like say Fayga Ostrower. Based on the theories of the artist, intends to investigate how their own texts read his plastic production, heavily influenced by German Expressionism. The concernment of the research is in the approach how their publications favor the understanding of artistic making as a moment against the intuitive and the fullness of the original creation and true to the thought of the artist.
\end{abstract}

Keywords: visual arts - creativity - creation' process Fayga Ostrower - contemporary art

Resumo - A maneira como olhamos expressa nossa alma, por isso não há como desconsiderar a presença de processos intuitivos na criação de qualquer obra, como diria Fayga Ostrower. Partindo das teorias da artista, intenta-se investigar como seus próprios textos lêem sua produção plástica, extremamente influenciada pelo Expressionismo alemão. $O$ interesse da pesquisa está na abordagem de como suas publicações favorecem a compreensão do fazer artístico como momento de encontro ao intuitivo e à plenitude da criação original e fiel ao pensamento do artista.

Palavras-chave: artes visuais - criatividade-processo de criação - Fayga Ostrower - arte contemporânea

\section{INTRODUÇÃO}

A obra de Fayga Ostrower se debruça sobre duas grandes vertentes, elaboradas durante os oitenta anos de vida da artista: a plástica e a teórica. A produção artística é composta, em sua maioria, por desenhos, gravuras, aquarelas, encontrando-se também algumas jóias e estampas para tecidos. Nas publicações, vemos as reflexões sobre o processo criativo e leituras minuciosas de obras, do percurso de artistas e de seu processo criativo, do ensino das Artes Visuais e teoria das artes, decorrências de sua riquíssima experiência no fazer artístico.

Desde sua morte em 2002, a família vem se dedicando a preservar e a compartilhar o legado da artista, atitude nem sempre comum a herdeiros de patrimônios artísticos. Dessa forma, sua produção (e textos inéditos) tem vindo ao conhecimento público, possibilitando o acesso às conexões estabelecidas em seu processo criativo. Essa viabilidade também se estende a uma leitura mais completa das tessituras compostas por Fayga em sua obra, cheia de complexidades e possibilidades interpretativas. Representam uma só trama, coerente e expressiva, à espera da investigação, um continuum que se abre à proliferação de sua obra.

\section{A PRODUÇÃO DE FAYGA}

De origem judia, Fayga Perla Krakowski (Ostrower, a partir de seu casamento em 1938) chegou com sua família ao Brasil em 1934 refugiada do crescimento nazista na Alemanha. Logo na viagem de navio, já realizava retratos dos passageiros, inclusive a troco de chocolates que compartilhava com seus irmãos.

Em meio a uma vida restrita financeiramente que a fez trabalhar logo cedo, iniciou seus estudos em artes em 1939 na Sociedade Brasileira de Belas Artes, no Rio de Janeiro, com ênfase cada vez maior para a gravura, principalmente a partir de 1943 quando conhece o gravador austríaco Axel Leskoschek, influência preponderante no desenvolvimento da linguagem no Brasil.

Atuando como ilustradora inicialmente (1944 e 1945), passa a se dedicar integralmente à arte a partir de 1946 e à ministração de cursos práticos de desenho e gravura de 1950 a 1953. Após esse período, sua carreira como educadora é centrada na teoria e suas criações, na abstração presente, inclusive, em desenhos para tecidos e jóias.

De 1954 a 1970 ministra cursos de Composição, Estrutura Espacial e Expressão na Arte, Análise de Estilos, Teoria da Gestalt e Teoria da Percepção. No decorrer de sua vida recebeu inúmeros prêmios, reconhecimento nacional e internacional, destacando-se, dentre eles, o Grande Prêmio Internacional de Gravura na XXIV Bienal de Veneza, em 1858.

Sua grande experiência como artista, educadora e a consciência do papel de seu ofício junto à sociedade corroboraram para a construção de seu legado, presente não somente nas centenas de obras plásticas, como também nos seis livros que publicou: Criatividade e Processos de Criação (1977); Universos da Arte (1983); Acasos e Criação Artística (1990); Goya: artista revolucionário e humanista

\footnotetext{
${ }^{1}$ Joedy Luciana Barros Marins Bamonte, Bacharel em Artes Plásticas pela Universidade Presbiteriana Mackenzie, Mestre em Comunicação e Poéticas Visuais pela UNESP, Doutora em Ciências da Comunicação pela ECA-USP. Professora Assistente em RDIDP, vinculada à Universidade Estadual Paulista UNESP (DARG- FAAC), Av. Eng Luiz Edmundo Carrijo Coube, nº 14-01, 17033-360, Vargem Limpa, Bauru, São Paulo, Brasil, joedy@ faac.unesp.br
} 
(1997); A Sensibilidade do Intelecto (1999) e o póstumo A Grandeza Humana: cinco séculos, cinco gênios da arte (2003).

\section{AS RELAÇÕES TRANSDISCIPLINARES PRESENTES NO PROCESSO CRIATIVO: ENTRE O INDIVÍDUO E O SEU EXTERIOR}

Fayga é transdisciplinar. Leva sua experiência nas Artes Visuais para todas as áreas do saber, acreditando que não são privilégios de sua área de atuação. A criação, a criatividade, o fazer artístico estavam relacionados para ela da seguinte forma:

As potencialidades e os processos criativos não se restringem, porém, à arte. (...) $\mathrm{O}$ criar só pode ser visto num sentido global, como um agir integrado em um viver humano. De fato, criar e viver se interligam. (OSTROWER, 1987, p. 5)

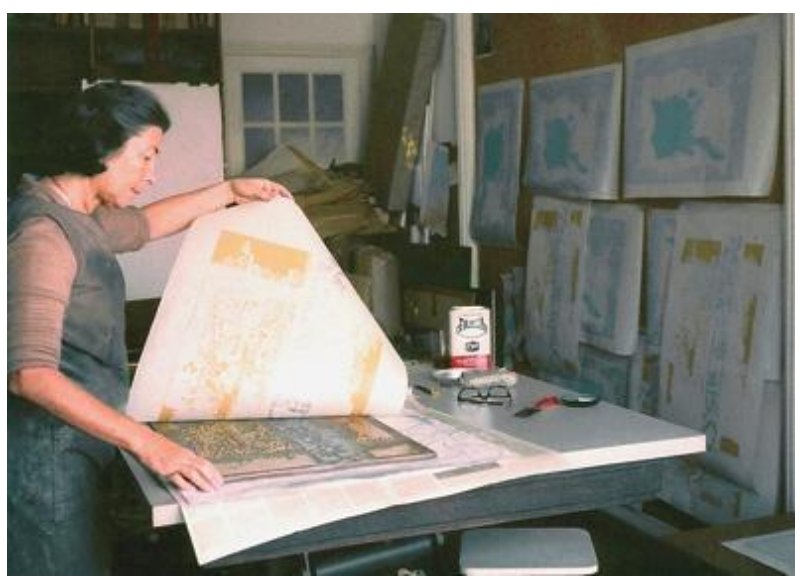

FIGURA 1

Fayga Ostrower em seu ateliê, Rio de Janeiro, 1982 (http://www.faygaostrower.org.br/acervo/aquarelas?start=60)

Em seus livros, a artista faz uma abordagem do momento criativo como um compartilhar de vida, organização e conhecimento, de si mesmo e do outro. Um caminho aberto para o ser humano viver em sua integralidade. Para ela, formular questionamentos e buscar respostas faz parte da essência humana, em um ir e vir onde o ser se descobre e se conhece, estendendo-se ao outro e ao seu entorno. Há uma dinâmica na qual o intuitivo ordena e sinaliza soluções, seja na ciência ou nas artes, sendo a última privilegiada com esses sinais, agregados à expressão e à manifestação dos sentidos. De maneira complexa, o comportamento criativo está fundamentado em uma seletividade espontânea sustentado por influências externas.
Para ela, cada um de nós absorve, normalmente, das influências somente aquilo com que já tem afinidade. "Para nos envolver e orientar nossas potencialidades, as influências teriam que surgir em termos de um apelo afetivo.“ (OSTROWER, 1991, p.148). Assim, além do intuitivo, o afetivo também estaria agregado aos processos da criação plástica:

Conhecer se dá também num em um nível afetivo. Se você tirar esse nível afetivo você não é capaz de criar. Por que a criação é uma questão de intuição. Isso um cientista lhe vai confirmar do mesmo jeito que um artista. (...) (http://www.itaucultural.org.br/aplicexternas/enciclopedia _ic/index.cfm?fuseaction=artistas_biografia\&cd_verbete $=1729 \& 1$ st_palavras $=\& c d \_i d i o m a=28555 \& c d \_i t e m=1$ )

Fayga aborda a obra artística em suas questões teóricas, compositivas e estruturais com a propriedade garantida por sua produção plástica, estabelecendo correspondências entre elementos expressivos presentes na criação, momentos distintos da história da arte e aspectos específicos de obras de artistas renomados. Na problemática da percepção e das formas de linguagem, prioriza a teoria da Gestalt e alcança as várias linguagens e formas expressivas observadas na trajetória das Artes Visuais.

Para a publicação de seus textos, observa-se, principalmente em Acasos e Criação Artística e A Sensibilidade do Intelecto, a presença de um grupo de profissionais de diversas áreas, em sua equipe de trabalho consultada por Fayga para reflexões sobre cada capítulo, o que, segundo a autora, permitiu

(...) discussões fascinantes, que nos levaram muitas vezes a outras disciplinas e outras áreas do conhecimento. (...) sugestões valiosas, que enriqueceram não somente o texto do livro, mas também minha própria visão dos problemas artísticos (OSTROWER, 1998, p. XVI)

Para a compreensão da amplitude visualizada pela artista nas Artes Plásticas, cita-se alguns nomes, junto a sua atuação profissional: Luiz Alberto Oliveira, físico nuclear, cosmólogo e filósofo; Roberto Santoro de Almeida, psiquiatra e musicólogo; Isabel Gurgel Valente, psicanalista; Gilda Salem Szklo, professora de literatura brasileira e francesa.

Dessa forma, Ostrower faz de seu texto um veículo à disposição da transdisciplinaridade, reconhecendo na arte a projeção do homem como um todo e a possibilidade de se reconhecer na arte, encontrando questionamentos e respostas para sua essência. $\mathrm{Na}$ arte, o pensamento como um todo é materializado.

CONSIDERAÇÕES SOBRE O PERCURSO DA OBRA DA ARTISTA 
A natureza criativa para Fayga Ostrower excede os limites das Artes. É intrínseca ao ser humano, garantindo-lhe um enriquecimento moral, espiritual, psíquico.

Sua obra foi grandemente influenciada por Käthe Kolwitz e Paul Cézanne, os quais lhes deixaram marcas definitivas não somente formais quanto contextuais. Das obras de Kolwitz herdou a ótica social sobre a arte enquanto elemento transformador, presentes no traço potente da gravura. De Cézanne, trouxe para sua obra a abstração como excelência, elemento depurador da experiência perceptiva, sensorial.

Ao trabalhar com a gravura abstrata a partir de meados da década de 1950, abandona duas características preponderantes no período no Brasil: o contexto social abordado pelos gravuristas e a tendência concretista que identificava o distanciamento da representação realista com formas geométricas.

Dessa forma, a artista se deparou com críticas ao inovar e exceder seu período em criações cheias de lirismo ao utilizar a cor como elemento prioritário. Os desenhos são compostos como decorrência de matizes que evocam a expressividade e se aproximam da música e se distanciarem do realismo. Para ela, "É em função da vida que surgem as formas expressivas da arte." (OSTROWER, 1998, p.4)

$\mathrm{Na}$ experiência artística, como criadora Fayga encontra a excelência como teórica. Em sua produção compreende as diferentes vertentes artísticas, seu grau de complexidade, as nuances marcadas por cada momento histórico, estético. Identifica-se com o momento de criação, com os processos necessários para a materialização da obra, coloca-se no lugar do artista, pois conhece os procedimentos dos quais se utiliza em sua poética, pois deles também se utiliza. Ao compreender a arte em sua totalidade atuou como mediadora e facilitadora para os que dela queriam se aproximar para crescimento humano ou para a formação de futuros artistas.

Além do olhar estrangeiro, Fayga também trouxe a visão específica da mulher no século XX. É assim que faz a leitura das crianças brincando no morro, das mães aconchegando seus bebês, da comunidade menos favorecida trabalhando, da paisagem, de seu próprio contexto familiar. Inicialmente realista, o traço se transforma em gestos grandiosos, nuances exuberantes, marcas minuciosas que igualmente trazem a presença da alma feminina, não restrita, mas abrangente, generosa, harmoniosa, graciosa. Nesse aspecto, ressalta-se o depoimento da própria artista durante uma entrevista:

A criação não é um aspecto infantil, nem juvenil. É um aspecto de maturidade. (...) O mais importante para um artista, como para qualquer ser humano, é conservar essa capacidade de crescer, a possibilidade de descobrir essa surpresa que você tem em criança, diante desse mundo que você quer compreender. Olha, essa surpresa continua junto com o artista, você se surpreende continuamente. Isso que é importante, essa vulnerabilidade que você preserva diante da vida, diante desse mistério incrível que é viver." (VICALVI, 1998)

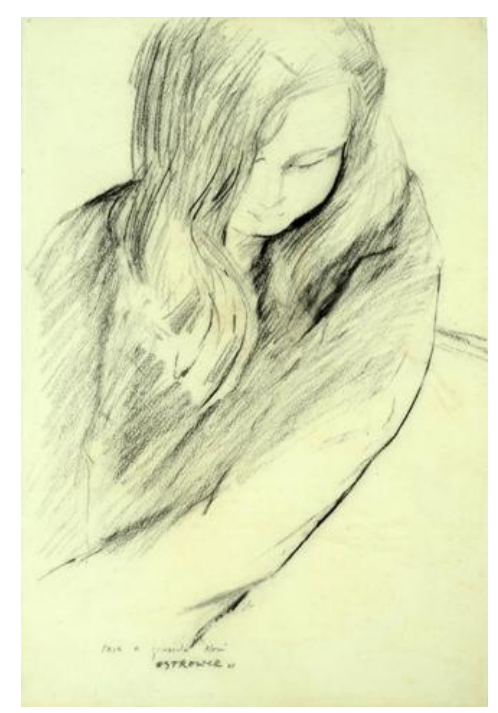

FIGURA 2

“Noni”, Fayga Ostrower, 1965; pastel oleoso sobre papel; 47,0 x 32,0 cm (http://www.faygaostrower.org.br/acervo/desenhos?start=60)

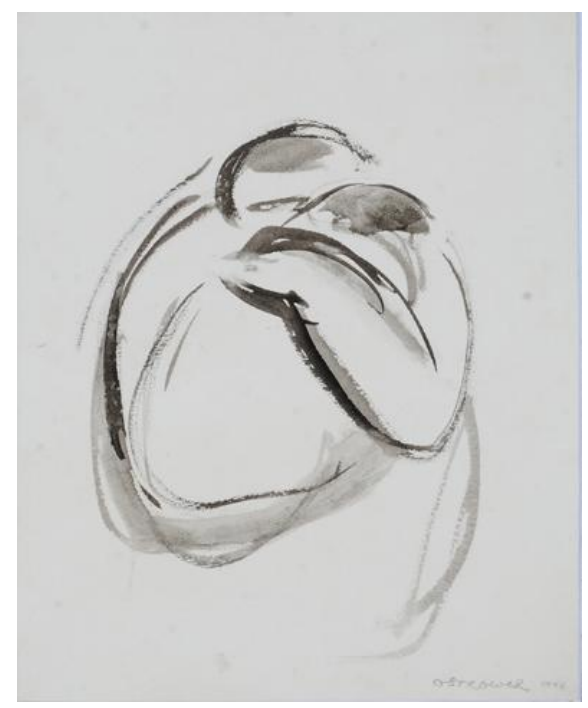

FIGURA 3

Sem Título, Fayga Ostrower, 1947; aguada de nanquim s/ papel; 25 x $18 \mathrm{~cm}$ (http://www.faygaostrower.org.br/acervo/desenhos? start=90)

\section{(C) 2014 WCCA}

\section{World Congress on Communication and Arts}

April 20 - 23, 2014, Vila Real, PORTUGAL 


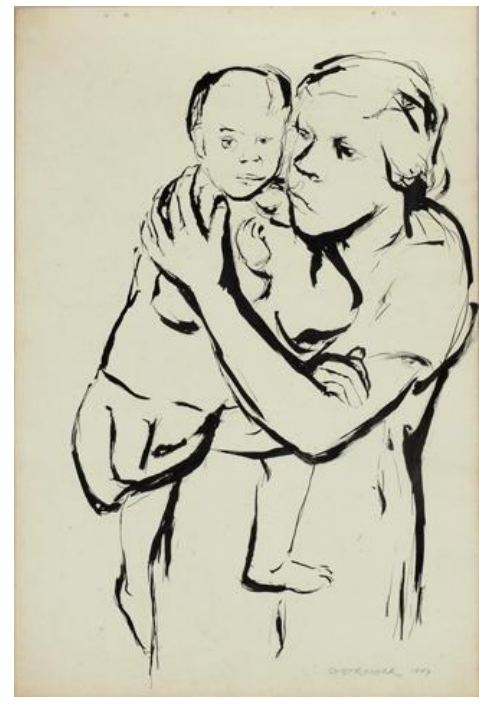

FIGURA 4

Sem Título, Fayga Ostrower, 1947; nanquim sobre papel; 44,0 x 28,0 cm (http://www.faygaostrower.org.br/acervo/desenhos?start=90)

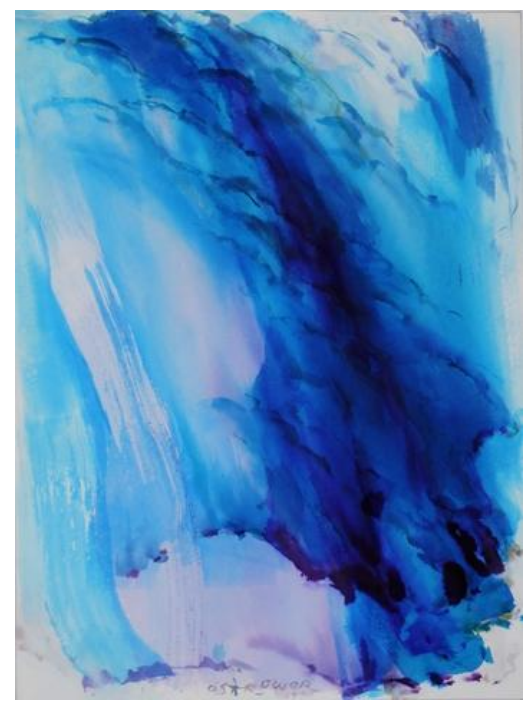

FIGURA 5

"Tempestade"; Fayga Ostrower; aquarela sobre papel Arches, 1999, $75,5 \times 56,5 \mathrm{~cm}$

(http://www.faygaostrower.org.br/acervo/aquarelas?start=60)

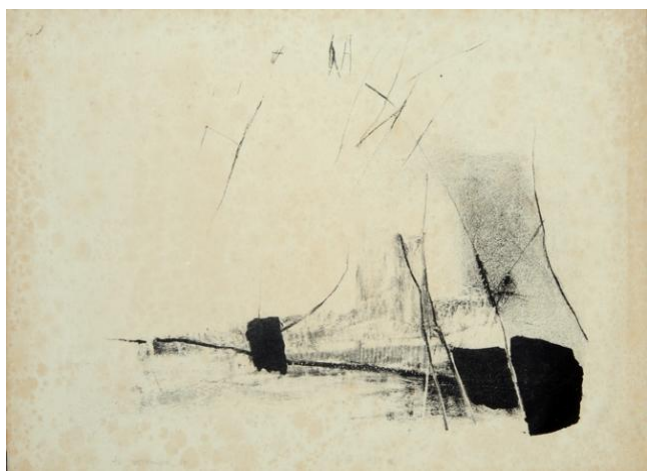

FIGURA 6

Sem título, Fayga Ostrower, 1957; litografia a cores sobre papel Arches $37,7 \times 56,4 \mathrm{~cm}$

(http://www.faygaostrower.org.br/acervo/gravuras?start=120)

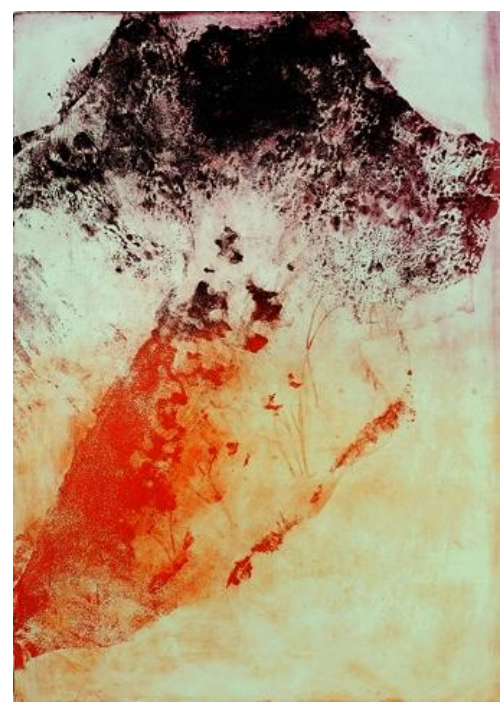

FIGURA 7

Sem título, Fayga Ostrower, 1995; Água-tinta a cores sobre papel; 54,3 x $37,0 \mathrm{~cm}$ (http://www.faygaostrower.org.br/acervo/gravuras?start=120)

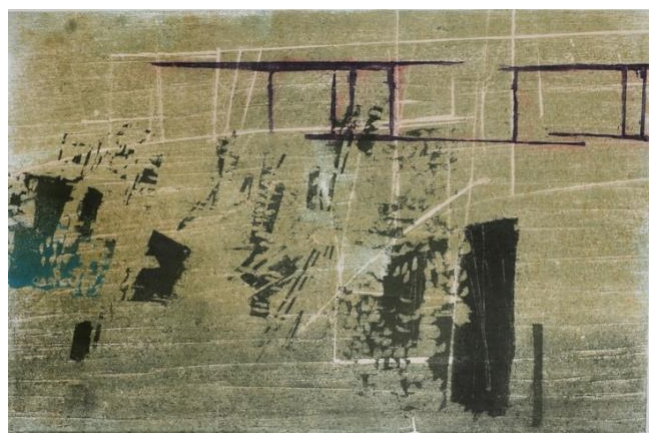

FIGURA 8

Composição Abstrata, Fayga Ostrower, 1990; Xilogravura a cores sobre papel de arroz; 44,0 x $66,0 \mathrm{~cm}$

(http://www.faygaostrower.org.br/acervo/gravuras?start=330) 


\section{CONSIDERAÇÕES FinAIS}

Sendo impossível trabalhar toda a amplitude da obra da artista, o espaço do presente texto pretendeu abordar a importância de Fayga Ostrower enquanto artista e teórica, em atividades totalmente vinculadas em enriquecedoras entre si. Por ter se dedicado de maneira apaixonada às Artes e pela consciência que possuía como artista e como ser humano, toda sua obra necessita ser esmiuçada e investigada de maneira intensa e profunda, concernente à potência com a qual foi construída e legada à sociedade. Nesse contexto, o caráter transdisciplinar ganha voz de maneira singular, algo possível diante da visão abrangente que a artista tinha e da maturidade evidenciada em toda sua produção, que the permitiu conhecer e compartilhar o saber em textos verbais e não-verbais.

\section{REFERÊNCIAS}

OSTROWER, Fayga. Criatividade e processo de criação. 8 ed. Petrópolis: Vozes, 1991.

OSTROWER, Fayga. A sensibilidade do intelecto. 9ed. Rio de Janeiro: Elsevier, 1998.

CARVALHO, Walter, JARDIM, João. Janela da alma. Filme color, 2002. Europa Filmes. 73 min. Brasil.

INSTITUTO Fayga Ostrower. Disponível:

<http://faygaostrower.org.br>. Acesso em: 29 nov 2013.

OSTROWER, Noni (coord.). Os caminhos de Fayga

Ostrower. Rio de Janeiro: Caixa Cultural, 2006.

TÁVORA, Maria Luiza Luz. Fayga Ostrower e a gravura abstrata no Brasil. Disponível em:

<http://www.iar.unicamp.br/dap/vanguarda/artigos_pdf/mari a_luiza.pdf>. Acesso em: 29 nov 2013.

VICALVI, Cacá. $O$ trabalho e a vida de Fayga Ostrower, depoimentos da artista, professora e escritora em seu espaço de trabalho. Rede SESCSENAC de televisão.

Disponível em:

http://artenaescola.org.br/dvdteca/catalogo/dvd/18/. Acesso em: 29 nov 2013. 